\title{
Lung Function Decline in 4-Monthly Repeated Spirometric Measurements: Due to Silt Aerosol Exposure or Decreasing Effort?
}

\author{
K. Radon R. Wegner D. Szadkowski \\ Ordinariat für Arbeitsmedizin der Universität und Zentralinstitut für Arbeitsmedizin der Freien und Hansestadt \\ Hamburg, Deutschland
}

\section{Key Words}

Lung function decline $\cdot$ Silt aerosols · Effort ·

Longitudinal study possible decline of effort in frequently repeated measurements may result in overestimating potential effects of occupational exposure.

Copyright (C2000 S. Karger AG, Basel

\begin{abstract}
Background: Workers on dredgers and lighters on rivers are exposed to the inhalation of aerosols and dusts. Objective: The aim of this study was to investigate effects of river silt aerosol and dust exposure on the respiratory health of dredging employees. Methods: Six examinations were performed over a period of 2 years at 4-monthly intervals in 54 seamen with higher silt aerosol exposure and 36 controls of the same employer. Results: No significant differences could be observed between the groups at any time of the study but there was an unexpected significant decrease in the age-corrected expiratory vital capacity (FVC), forced expiratory volume in $1 \mathrm{~s}\left(\mathrm{FEV}_{1}\right)$ and midexpiratory flow rate $\left(\mathrm{MMEF}_{25 / 75}\right)$ over the six series in both groups. This may indicate a loss of effort of the participants in re-examinations since biological and technical influences were highly unlikely to be the cause of these findings. Conclusions: Ignoring this
\end{abstract}

\begin{tabular}{ll}
\hline KARGER & ( 2000 S. Karger AG, Basel \\
0025-7931/00/0671-0041\$17.50/0 \\
$\begin{array}{l}\text { Fax +4161306 1234 } \\
\begin{array}{l}\text { E-Mail karger@karger.ch } \\
\text { www.karger.com }\end{array}\end{array}$ & $\begin{array}{l}\text { Accessible online at: } \\
\text { www.karger.com/journals/res }\end{array}$
\end{tabular}

\section{Introduction}

In the harbour of Hamburg, it is necessary to dredge the river Elbe to maintain a sufficient depth for shipping traffic. Therefore, approximately 2.5 million $\mathrm{m}^{3}$ of mud are dredged annually. Roughly half of it consists of silt with $20 \%$ of the particles $<20 \mu \mathrm{m}$. Most components of the organic and inorganic pollution of the river water, especially heavy metals, are bound to this fraction [1].

Workers on the respective dredgers and lighters are exposed to the inhalation of aerosols and dusts, potentially containing heavy metals (especially lead, arsenic, cadmium, chromium, nickel, mercury), and e.g. nitrates, phosphates, polychlorinated biphenyls, and polycyclic aromatic hydrocarbons in low concentrations. A longitudinal design was chosen to assess the effects of occupational exposure on the respiratory health, taking into

Katja Radon

Institute of Occupational and Environmental Medicine

Ludwig Maximilians University Munich

Ziemssenstrasse 1, D-80336 München (Germany)

Tel. +49 895160 2794, Fax +49 895160 4444, E-Mail K.Radon@lrz.uni-muenchen.de 
Table 1. Characteristics of the subjects at the beginning of the survey

\begin{tabular}{llll}
\hline & $\begin{array}{l}\text { Exposed subjects } \\
(\mathrm{n}=54)\end{array}$ & $\begin{array}{l}\text { Controls } \\
(\mathrm{n}=36)\end{array}$ & $\mathrm{p}$ value \\
\hline Age, years & $46.3 \pm 9.8$ & $43.1 \pm 11.6$ & 0.16 \\
Duration of employment, years & $10.3 \pm 7.2$ & $6.9 \pm 8.1$ & 0.04 \\
Current smokers, \% & 63.0 & 27.8 & 0.002 \\
Cigarettes per day & $19.5 \pm 8.1$ & $18.9 \pm 6.5$ & 0.83 \\
Years smoked & $26.8 \pm 9.9$ & $23.3 \pm 10.0$ & 0.36 \\
Body mass index & $27.3 \pm 3.7$ & $27.8 \pm 3.8$ & 0.51 \\
\hline
\end{tabular}

account seasonal effects and changing of the dredging locations.

Thus, the intervals between the examinations had to be determined. Therefore, the frequency of changing the dredge place and the acute or long-term character of the supposed effect had to be considered. Since the particular effects of river silt aerosols and dusts had not been studied before, the latter was difficult to evaluate. In most longterm studies on effects of occupational exposure on respiratory health, intervals between 1 and 10 years were chosen [e.g. 2-4]. To detect short-term effects of inhaled aerosols and dusts at different sites of the river, these intervals were considered too long. Therefore, lung function measurements were performed every 4 months over a 2-year period.

\section{Subjects and Methods}

\section{Subjects}

100 male employees at different working places in the harbour of Hamburg were initially enrolled and 90 participated in all six examinations. Only data obtained in these subjects are presented in this paper. 54 were expected to have a higher exposure to silt aerosols and dusts (seamen on lighters, dredgers, and suction dredgers; exposed group), and 36 served as an internal control group (office workers, captains, engineers, door-keepers; controls).

\section{Lung Function Measurements}

Spirometry was carried out in all subjects as recommended by the American Thoracic Society [5]. Inspiratory and expiratory vital capacity (IVC and FVC), forced expiratory volume in $1 \mathrm{~s}\left(\mathrm{FEV}_{1}\right)$,

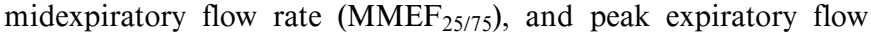
(PEF) were determined with a transportable spirometer (Flowscreen II, Jaeger, Würzburg, Germany). The equipment was volume-calibrated before every testing procedure, and measurements were electronically transformed to body temperature and pressure-saturated conditions. Lung function tests were performed with the subject in the sitting position using a noseclip. A minimum of three technically satisfactory manoeuvres were performed with the two best-acceptable $\mathrm{VC}$ and $\mathrm{FEV}_{1}$ measurements varying by $10 \%$ at most. Maximum
IVC, FVC, FEV ${ }_{1}$ and PEF values were used for analysis. To avoid technical mistakes only one spirometer was used for all measurements, it was volume-calibrated every day and one experienced and closely supervised technician performed all spirometric measurements. All subjects were asked about their smoking habits. In series three to six, 43 participants of the exposed group were additionally classified by a questionnaire according to higher (dredging silt) or low (holidays, illness, dredging sand) silt exposure within 2 weeks preceding the examinations.

\section{Statistical Analysis}

Standard methods of statistical analyses were used, such as $t$ test for independent and dependent variables, cross-tabulation, multiple regression, analysis of variances and post hoc comparison by Tukey test. Statistical significance was assumed at $p<0.05$. In this report all references of the lung function are given as percentage of the predicted value [6].

\section{Results}

\section{Study Population}

Table 1 shows data characterizing the different exposure groups at the beginning of the survey. There were no differences between the groups in age, years of smoking, number of cigarettes per day, and body mass index. Exposed subjects had a significantly higher duration of employment $(p<0.05)$, and there was a higher percentage of smokers among them $(\mathrm{p}<0.01)$.

\section{Lung Function Tests}

The results for IVC and FVC did not differ except lower mean IVC than FVC values (3.5\% predicted, nonsignificant). Therefore, only the results for FVC are presented in the following passages. No significant differences in lung function values were observed between the exposed and the control group at the first examination (table 2) or at either of the subsequent examinations. When dividing the groups according to smoking habits, no significant 
Table 2. Mean and standard deviation (\% predicted) for the spirometric indices of the first examination

\begin{tabular}{|c|c|c|c|c|c|c|}
\hline & \multicolumn{2}{|l|}{ All subjects } & \multicolumn{2}{|l|}{ Non-smokers } & \multicolumn{2}{|l|}{ Current smokers } \\
\hline & exposed $(n=54)$ & controls $(n=36)$ & exposed $(n=20)$ & controls $(n=26)$ & exposed $(n=34)$ & controls $(n=10)$ \\
\hline FVC & $106.1 \pm 16.7$ & $106.9 \pm 14.0$ & $107.8 \pm 21.3$ & $108.3 \pm 15.0$ & $105.0 \pm 13.5$ & $103.4 \pm 10.7$ \\
\hline $\mathrm{FEV}_{1}$ & $103.6 \pm 18.3$ & $103.7 \pm 18.3$ & $107.0 \pm 24.3$ & $106.1 \pm 17.6$ & $101.6 \pm 13.7$ & $97.4 \pm 19.7$ \\
\hline $\mathrm{MMEF}_{25 / 75}$ & $91.8 \pm 30.1$ & $93.3 \pm 34.6$ & $99.6 \pm 34.7$ & $96.7 \pm 31.4$ & $87.3 \pm 26.6$ & $84.5 \pm 42.2$ \\
\hline PEF & $113.1 \pm 24.5$ & $115.9 \pm 24.4$ & $115.5 \pm 31.1$ & $117.8 \pm 24.3$ & $111.7 \pm 20.0$ & $110.8 \pm 25.5$ \\
\hline
\end{tabular}

Differences between exposed group and controls: nonsignificant.

Table 3. Multiple regression analysis of lung function parameters as dependent variables (\% predicted) and body mass index, duration of employment (years), smoking, season and exposure group (upper panel) or higher silt exposure within the preceding 2 weeks (lower panel) as the predictor variables (3rd examination)

\begin{tabular}{|c|c|c|c|c|c|c|c|c|}
\hline & \multicolumn{2}{|l|}{ FVC } & \multicolumn{2}{|c|}{$\mathrm{FEV}_{1}$} & \multicolumn{2}{|c|}{$\mathrm{MMEF}_{25 / 75}$} & \multicolumn{2}{|l|}{ PEF } \\
\hline & $\beta$ & $\mathrm{p}$ & $\beta$ & $\mathrm{p}$ & $\beta$ & $\mathrm{p}$ & $\beta$ & $\mathrm{p}$ \\
\hline \multicolumn{9}{|l|}{ All subjects $(n=90)$} \\
\hline Body mass index & -0.25 & 0.02 & -0.20 & 0.07 & -0.08 & 0.48 & -0.02 & 0.83 \\
\hline Duration of employment & 0.07 & 0.55 & 0.15 & 0.17 & 0.06 & 0.60 & 0.16 & 0.15 \\
\hline Smoking & -0.10 & 0.38 & -0.18 & 0.12 & -0.14 & 0.23 & -0.08 & 0.47 \\
\hline Season (summer/winter) & -0.03 & 0.81 & 0.03 & 0.81 & 0.10 & 0.40 & 0.05 & 0.69 \\
\hline Exposure group & 0.10 & 0.38 & 0.04 & 0.71 & 0.08 & 0.53 & 0.09 & 0.44 \\
\hline \multicolumn{9}{|c|}{ Subjects classified according to silt exposure $(n=43)$} \\
\hline Body mass index & -0.15 & 0.48 & -0.09 & 0.69 & -0.03 & 0.90 & -0.03 & 0.89 \\
\hline Duration of employment & -0.04 & 0.81 & 0.03 & 0.86 & 0.01 & 0.95 & -0.01 & 0.94 \\
\hline Smoking & 0.03 & 0.87 & -0.07 & 0.69 & -0.09 & 0.60 & 0.03 & 0.84 \\
\hline Season (summer/winter) & 0.08 & 0.65 & 0.18 & 0.29 & 0.30 & 0.08 & 0.27 & 0.12 \\
\hline \multicolumn{9}{|l|}{ Higher silt exposure within } \\
\hline the preceding 2 weeks & -0.05 & 0.79 & -0.06 & 0.79 & 0.02 & 0.90 & -0.11 & 0.57 \\
\hline
\end{tabular}

effect of occupational exposure on lung function was found at any time of the investigation.

In a multiple regression model with lung function parameters as dependent variables and duration of employment, body mass index, smoking habit, season, and exposure group as independent variables only the body mass index showed a significant influence on FVC \% predicted. Taking into account periods of higher silt exposure in the preceding 2 weeks in the exposed group no significant relationship could be observed (see table 3 for the third examination).

Comparing the six examinations by multiple analysis of variances with exposure group and smoking status as independent variables, no effects of exposure were seen.
The analysis of variances over the six series showed no differences between the exposure groups. As shown in figure 1, there was a significant decline of FVC $\%$ predicted, $\mathrm{FEV}_{1} \%$ predicted and $\mathrm{MMEF}_{25 / 75} \%$ predicted in both groups comparing the first with any of the following examinations. The decreases in the following series were smaller and not significant except the second examination compared to the fifth regarding FVC \% predicted and compared to the fifth and sixth for $\mathrm{MMEF}_{25 / 75} \%$ predicted. No significant decline could be observed among $\mathrm{PEF} \%$ predicted. The same results were seen when analyzing the data for smoking and nonsmoking subjects but FVC only decreasing significantly over the time in nonsmokers. 

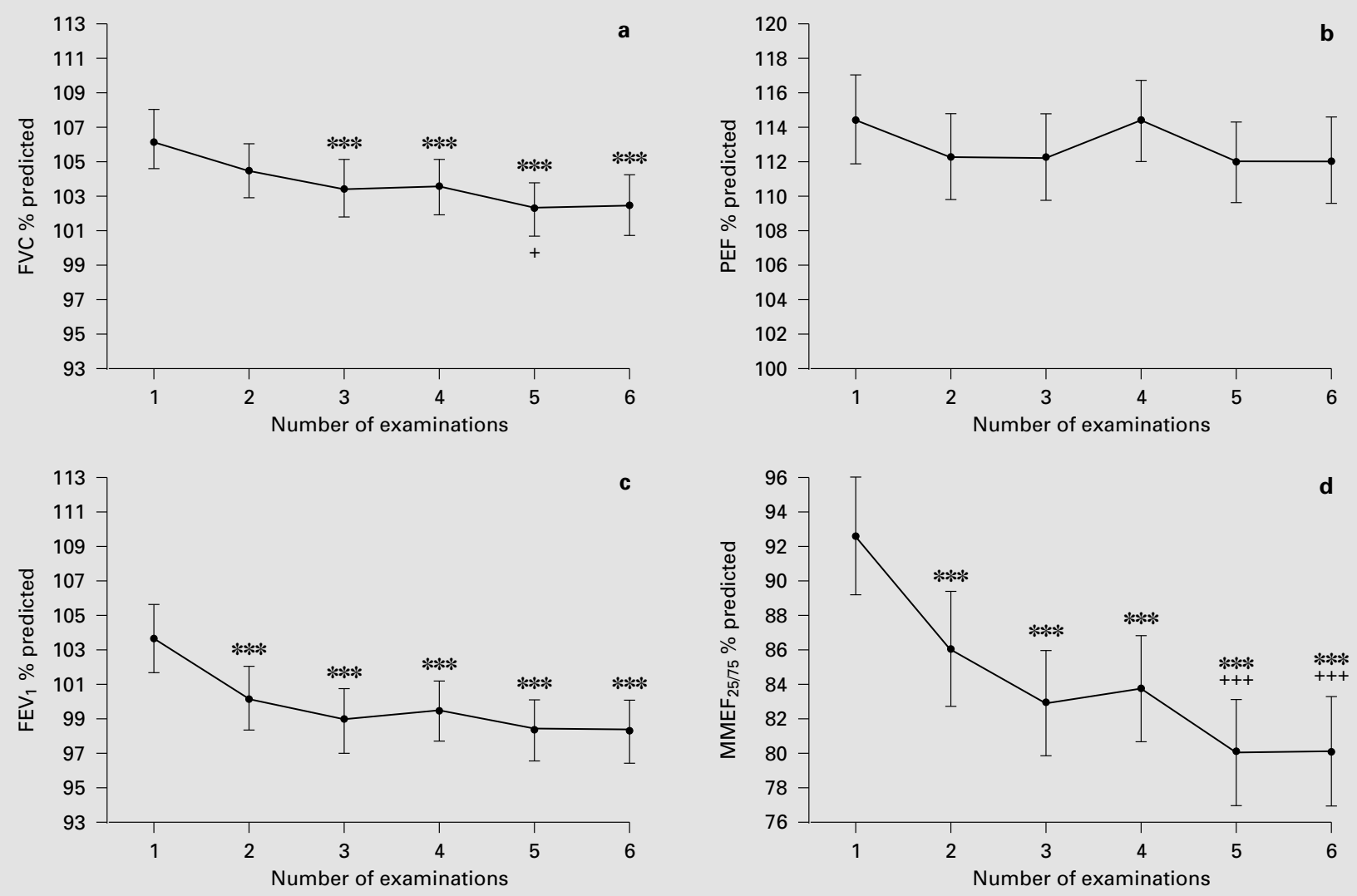

Fig. 1. Mean changes in spirometric indices over the six series $( \pm \mathrm{SEM}) . \mathrm{n}=90$ in all groups. $* * * \mathrm{p}<0.001$ vs. 1 st examination; ${ }^{+} \mathrm{p}<0.05 ;{ }^{+++} \mathrm{p}<0.001$ vs. 2 nd examination. $\mathbf{a} \mathrm{F}=5.30 . \mathbf{b} \mathrm{F}=1.57 . \mathbf{c} \mathrm{F}=11.46 . \mathbf{d} \mathrm{F}=14.15$.

\section{Discussion}

The focus of this study was to assess pulmonary function of seamen exposed to river silt over a period of 2 years. Regardless of exposure, a significant decline of $\mathrm{FEV}_{1}$ and $\mathrm{MMEF}_{25 / 75}$ was observed between the first and second examination; for FVC this decline was seen between the first and third examination. To establish a relationship between higher silt exposure and these lung function decrements, the proportion of subjects with higher silt exposure was compared within the second group at different times of the study. However, the proportion of subjects with a higher silt exposure did not differ significantly between the different investigations. Thus, there is no evidence for an effect of silt exposure in the studied group. Only one other study on river silt exposure could be found in the literature performed on residents near the desiccated Old Wives Lake [7]. High concentrations of sodium, magnesium, sulphate, chloride, phosphorus, and ammonia were reported in the air. Comparable to the present study, no significant effects of exposure on lung function results were observed. In contrast to our survey the design of the Gomez study was cross-sectional focusing on residents.

However, a significant decline from the first to the following series was detected on the spirometric parameters IVC, FVC, FEV 1 and $\mathrm{MMEF}_{25 / 75}$. The effect was mainly observed between the first and the second investigation and might have been attributed to occupational exposure if the beginning of the study were the beginning of exposure for the studied group. Conversely, the mean duration of employment at the start of the investigation was 11.1 years for the exposed subjects and 6.4 years for the controls. Thus the lung function decline described above is 
unlikely to be due to exposure to silt aerosols. Hence, it has to be concluded that working in areas exposed to river silt aerosols does not increase the risk of respiratory impairment. The reason for the lung function decline over the six series might be an interesting topic for further longterm studies on effects on lung function. In the present study, smoking could be excluded as a reason for our finding, because the lung function decline was also observed when only nonsmokers were analyzed. Wang et al. [2] described a strong influence of weight gain on the rate of $\mathrm{FVC}$ and $\mathrm{FEV}_{1}$ decline in longitudinal lung function studies. Repeating the multiple analysis of variances for lung function changes over the six examinations with body weight as a changing covariable no influence of body weight could be confirmed. Thus, changes in body weight do not explain the observed decrease in lung function values.

The reasons for variation of intraindividual lung function measurement can be divided into biological and technical components [e.g. 8-10]. Biological variations in airway tone occur within relatively short periods (hour-tohour, day-to-day, and month-to-month) [10]. One possible reason for the significant variation between the examinations could be the time of the year. This could not be confirmed in this investigation by a multiple regression model taking the season into account (table 3 ). Due to the fact that the mean decline in $\mathrm{FEV}_{1}$ of the present study was $188 \mathrm{ml}$ and this difference between the first and second examination was significant, it may be assumed that the variation in lung function over the time is not only caused by biological effects. Several technical components may have influenced our findings. One possible factor is that the quality of the lung function manoeuvres could have decreased over time because of decreasing efforts of the technician. This appears unlikely since there was a relatively large decline between the first and the second investigation rather than a continuous decline over many sessions. The quality of performing spirometry is also indicated by the low average variation of PEF \% predicted, which varied by no more than $2.4 \%$ between the investigations.

However, the most likely explanation for the declining spirometric results is a decreasing effort of the participants. There are three different types of breathing efforts during spirometry tests: (1) depth of inhalation; (2) force of exhalation, and (3) completing the exhalation (end of test criteria). If the force of exhalation had been submaximal, only the PEFs would have been lower while the FVCs would be the same. If the exhalation had been incomplete, only the FVCs would have been lower. Therefore, our data suggest a lower inhalation effort in the second to the sixth series resulting in proportionally lower $\mathrm{FEV}_{1} \mathrm{~S}$ and FVCs compared to constant PEF results.

In conclusion, no longitudinal lung function decline was observed due to occupational exposure to river silt aerosols. For the total group there seems to be a decline in effort taking short periods within re-examination. Ignoring this decrease of effort in short and often repeated measurements may result in overestimating exposure effects.

\section{Acknowledgement}

This study was supported by the 'Amt für Strom und Hafenbau der Wirtschaftsbehörde der Freien und Hansestadt Hamburg'. The authors thank Mrs. Nern for performing lung function testing, Mrs. Krause for data management, Anna Schottky for language assistance, and Dennis Nowak for his comments. We also thank the workers for their participation.

\section{References}

1 Wegner R, Heinrich-Ramm R, Seemann B Poschadel B, Szadkowski D: Innere Schwermetallbelastung bei Beschäftigten mit Elbschlickexposition. 37. Jahrestagung der Deutschen Gesellschaft für Arbeitsmedizin und Umweltmedizin e.V. Verhandlungen der deutschen Gesellschaft für Arbeitsmedizin e.V. Fulda, Rindt, 1997, pp 327-334.

2 Wang M-L, McCabe L, Hankinson JL, Banks DE: Longitudinal and cross-sectional analyses of lung function in steelworkers. Am J Respir Crit Care Med 1996;153:1907-1913.

3 Ostiguy G, Vaillancourt C, Begin R: Respiratory health of workers exposed to metal dusts and foundry fumes in a copper refinery. Occup Environ Med 1995;52:204-210.

Lung Function Decline in Repeated

Spirometric Measurements
4 Chan-Yeung M, Enarson DA, MacLean L: Longitudinal study of workers in an aluminum smelter. Arch Environ Health 1989;44:134139.

5 American Thoracic Society: Standardization of spirometry: 1994 update. Am J Respir Crit Care Med 1995;152:1107-1136.

6 Quanjer H, Tammeling GJ: Lung volumes and forced ventilatory flows. Eur Respir J 1993; 6(suppl 16):5-40.
7 Gomez SR, Parker RA, Dosman JA, McDuffie $\mathrm{HH}$ : Respiratory health effects of alkali dust in residents near desiccated Old Wives Lake. Arch Environ Health 1992;47:364-369.

8 Lebowitz MD: Age, period, and cohort effects. Am J Respir Crit Care Med 1996;154:S273S277.

9 Glindmeyer HW, Jones RN, Diem JE, Weill H: Useful and extraneous variability in longitudinal assessment of lung function. Chest 1987;92: 877-882.

10 Enright PL, Conett J, Kanner RE, Johnson LR, Lee WW: Spirometry in the Lung Health Study. II. Determinants of short-term intraindividual variability. Am J Respir Crit Care Med 1995;151:406-411. 